\title{
Lutas operárias da Construção Civil no COMPERJ: questões para a ação sindical e a saúde dos trabalhadores
}

\author{
Civil Construction workers' struggles at COMPERJ: \\ issues for union action and occupational health
}

Hugo Pinto de Almeida (http://orcid.org/0000-0002-7531-793X) ${ }^{1}$

Kátia Reis de Souza (http://orcid.org/0000-0002-2084-2606) ${ }^{2}$

José Augusto Pina (http://orcid.org/0000-0003-3204-2240) ${ }^{2}$

${ }^{1}$ Programa de PósGraduação em Saúde Pública, Escola Nacional de Saúde Pública Sergio Arouca, Fundação Oswaldo Cruz. R. Leopoldo Bulhões 1480, Manguinhos. 21041210 Rio de Janeiro RJ Brasil. hugopa_rj@yahoo.com.br

${ }^{2}$ Centro de Estudos da Saúde do Trabalhador e Ecologia Humana, Escola Nacional de Saúde Pública Sergio Arouca, Fundação Oswaldo Cruz. Rio de Janeiro RJ Brasil.

\begin{abstract}
The Rio de Janeiro Petrochemical Complex is one of the most significant heavy civil construction projects in Brazil. In 2014, we witnessed a significant strike for improved working conditions, which exposed different perspectives on workers and union representation. This stu$d y$ analyzes the meanings exposed by worker and union action in their implications for the collective defense of health in this strike experience. Qualitative social research employed investigation techniques such as participant observation, documentary survey, and interviews with workers and union leaders. The results produced a brief reconstruction of these struggles from the worke$r s^{\prime}$ perspective, analyzing the strike agendas such as the organization, mobilizations, and tensions between base workers and the union representing the category. Noteworthy was establishing a Base Commission decided by the very workers to act independently from the official union. We observed different responses from the State, companies, and the representative union to stifle the workers' struggle. Finally, we identified a struggle for improved working conditions and the collective defense of health by workers' organizations in the workplace. Key words Civil construction, Labor unions, Occupational health, Strikes, Outsourcing
\end{abstract}

Resumo O Complexo Petroquímico do Rio de Janeiro é uma das maiores obras da construção civil pesada no Brasil. Em 2014, foi realizada uma grande greve por melhorias nas condições de trabalho que expôs diferentes perspectivas acerca da representação dos trabalhadores e por motivo sindical. Este estudo analisa os sentidos postos pelos modos de ação operária e sindical em suas implicações à defesa coletiva da saúde nesta experiência grevista. Realizou-se uma pesquisa social de caráter qualitativo, lançando mão de técnicas de investigação como observação participante, levantamento documental e entrevistas com trabalhadores e dirigentes sindicais. Nos resultados, produziu-se uma breve reconstrução dessas lutas sob a perspectiva dos trabalhadores analisando as pautas de greve e a organização, mobilizações $e$ tensões presentes entre trabalhadores de base $e$ o sindicato da categoria. Ressaltou-se a formação de uma Comissão de Base, por decisão dos próprios operários, na tentativa de atuar de maneira autônoma ao sindicato oficial. Constatou-se diferentes respostas do Estado, empresas e sindicato representativo como forma de desarticular a luta dos trabalhadores. Ao fim, verificou-se luta para melhoria das condições de trabalho e defesa coletiva da saúde, por parte das organizações de trabalhadores nos locais de trabalho.

Palavras-chave Construção civil, Sindicatos, Saúde do trabalhador, Greve, Terceirização 


\section{Introdução}

No Brasil, nos anos 2000, observa-se um novo ciclo de grandes obras da Construção Civil (CC) pesada impulsionado pelo Estado, especialmente no segundo mandato do governo Luís Inácio Lula da Silva (2007-2010) com o lançamento, em 2007, do Programa de Aceleração do Crescimento (PAC). No plano da política econômica adotada pelos governos do Partido dos Trabalhadores (PT), instaurou-se um conjunto de medidas que flutuou entre a ortodoxia e a heterodoxia liberal, sem ameaçar a institucionalidade construída para o benefício da acumulação do capital financeiro' ${ }^{1}$.

Para Granemann, o sentido de desenvolvimento do PAC foi reduzido "(...) ao econômico, ao crescimento e à aceleração da acumulação capitalista, em consonância com o entendimento da economia burguesa sobre as funções que cabe ao Estado desenvolver"2 (p. 9). Nesse contexto, a história que se iniciou com o lançamento das obras do PAC teve consequências para a vida dos trabalhadores e são expressivas da relação entre Estado, Capital e Trabalho.

Do ponto de vista da história de luta da classe trabalhadora, do setor da CC pesada, foi promovido um conjunto de greves e manifestações no âmbito das obras do PAC. Tratavam-se de movimentos sociais procedentes da organização operária que viabilizaram diferentes modos de ações coletivas como forma de expressar suas demandas e de enfrentar adversidades no campo do trabalho e saúde ${ }^{3-5}$, com notoriedade na grande mídia, bem como na esfera política, jurídica e social. São exemplos os eventos ocorridos nas obras das Usinas Hidrelétricas de Jirau (2011), Santo Antônio (2011), Belo Monte (2011 e 2012), Complexo Portuário de Suape (2011) e Abreu e Lima $(2012)^{3,4}$.

Dados do DIEESE 6 comprovaram o aumento das greves no setor: em 2010, elas correspondiam a $3,1 \%$ do total de paralisações registradas no país; em 2011, esta proporção alcançou 9,4\%. Em números absolutos, nesse mesmo período, passou de 14 para 52 ocorrências, uma expansão de $270 \%$.

Nesse cenário, ganhou notabilidade a história dos trabalhadores da CC do Complexo Petroquímico do Rio de Janeiro (COMPERJ). Assim, como as demais obras do PAC ${ }^{3,4}$ o COMPERJ, localizado no município de Itaboraí, mobilizou dezenas de milhares de trabalhadores em grande parte operários corre-trecho ${ }^{7}$, assim denominados porque percorrem distintas obras da CC em busca de trabalho pelo país. Marx, ao ilustrar a lei geral da acumulação capitalista, caracteriza esse segmento de trabalhadores como parte da "infantaria ligeira do capital" ${ }^{8}$ (p. 602), lançada de uma região a outra conforme a conveniência das empresas.

Outra característica acerca da relação capital-trabalho presente nas obras do PAC ${ }^{3,4}$, como a do COMPERJ, é o uso da terceirização para a contratação de trabalhadores com objetivo de reduzir custos com a força de trabalho, ampliar lucros, aprofundar a fragmentação sindical e aumento da exploração capitalista9 .

O movimento de luta dos trabalhadores da CC do COMPERJ, ao longo da construção, foi constituído por conflitos abertos, com inúmeros protestos, rebeliões, greves, e antagonismo permanente entre capital e trabalho ${ }^{5}$. Nesse cenário de lutas, se destacou a mais longa greve do COMPERJ, entre janeiro e março de 2014, que expressou conflitos trabalhistas em termos das condições de trabalho, baixos salários e exaustivas jornadas de trabalho como também as ações do sindicato da categoria ${ }^{5,10}$.

A obra do COMPERJ contava com trabalhadores de diferentes categorias profissionais e distintas representações sindicais. Como categoria majoritária, os operários da CC eram oficialmente representados pelo Sindicato dos Trabalhadores nas Indústrias do Plano da Construção, Montagem e Manutenção Industrial de São Gonçalo, Itaboraí e Região (SINTICOM), filiado à Central Única dos Trabalhadores (CUT). A obra também possuía um contingente de trabalhadores efetivos da Petrobras (contratante da obra), representados pelo Sindicato dos Petroleiros do Rio de Janeiro (SINDIPETRO/RJ).

A greve dos operários do COMPERJ, de 2014, expôs diferentes perspectivas para representação dos trabalhadores e modos de ação sindical no enfrentamento dos conflitos entre capital e trabalho. Especificamente, os operários assumiram participação ativa na organização e condução da greve, e constituíram uma Comissão de Base (CB) separada do sindicato oficial, história que será aqui, brevemente, descrita e analisada sob a perspectiva dos próprios trabalhadores.

Hobsbawn ${ }^{11}$ afirma que não se pode negligenciar a percepção e a ação dos trabalhadores da base operária em relação as suas organizações. $\mathrm{O}$ autor ressalta a importância de se registrar a história dos movimentos operários sob o olhar de quem as vivencia de fato, no interior e na explosão da própria história.

Nesse sentindo, o presente estudo analisa as diferentes perspectivas vindas da representação 
No presente artigo assume-se a tese na qual os movimentos sociais e a resistência dos trabalhadores, que ocorrem em situações concretas, levam ao questionamento das contradições do processo de exploração capitalistas e auxiliam na emancipação social e humana, de modo a gerar mudanças e transformação social ${ }^{12}$. Ademais, admite-se a inteligência coletiva das lutas operárias, conforme asseguram teorias da tradição do materialismo histórico, haja vista que a ação de massa é educativa e produz conhecimento crítico sobre a realidade social, e potencializa a solidariedade de classe e a consciência política dos trabalhadores como sujeitos de mudanças históricas ${ }^{13,14}$.

Em se tratando do movimento de greve, compreende-se enquanto um espaço de experiência coletiva dos trabalhadores, no qual desenvolve-se a luta por direitos contrapondo-se a patrões e governos ${ }^{15}$. A greve pode ser considerada uma das formas de resistência aberta e questionamento operário na luta por melhores condições de trabalho e saúde ${ }^{3,4}$.

$\mathrm{O}$ presente estudo ancora-se no referencial teórico-metodológico da Saúde do Trabalhador (ST), em que se destacam os aportesda medicina social latino-americana ${ }^{12}$ e dos estudos operários italianos ${ }^{16}$. Estas perspectivas reconhecem que a saúde operária está fortemente relacionada às formas de resistência, mobilização e organização coletiva dos trabalhadores.

O campo de estudo foi realizado no território do próprio COMPERJ e a coleta de dados foi feita entre maio de 2014 e setembro de 2015 . Os procedimentos metodológicos utilizados foram a observação participante, entrevistas individuais com informantes-chave e levantamento documental. Em um primeiro momento, a entrada no campo compreendeu a participação em audiências públicas, assembleias da categoria e, posteriormente, visitas aos sindicatos. O principal objetivo deste momento foi adentrar na realidade, convivendo e estreitando os laços dentro daquele contexto social ${ }^{17}$, bem como identificar possíveis "informantes-chave"18.

$\mathrm{O}$ segundo momento da pesquisa abrangeu a realização de entrevistas com os informantes-cha-

$\mathrm{ve}^{18}$. Ao todo foram dez entrevistas, sendo cinco com trabalhadores da CC do COMPERJ, participantes do movimento de greve, um com SINTICOM e quatro com diretores do SINDIPETRO/RJ.

Quanto aos documentos levantados que serviram de base de análise do estudo, lançouse mão das Convenções Coletiva de Trabalho (2012-2016), materiais do movimento grevista do COMPERJ, boletins sindicais e atas das audiências públicas realizadas pelo Ministério Público do Trabalho (MPT).

No que tange à construção do corpo de análise de dados, utilizaram-se, conforme Brandão ${ }^{19}$, aquelas passagens mais fortes e poderosamente descritivas das entrevistas, denominadas "falas marcantes" visto que se repetem, tocam na mesma tecla e se diferenciam devido ao seu teor crítico. São escolhas que estão em consonância com o tema e objetivos do estudo.

Apesar de verificarmos distintas percepções entre os operários e sindicalistas tais passagens enfatizam suas respectivas experiências sociais e simbólicas, permitindo que os dados de pesquisa se tornem textos vivos sob a perspectiva da análise crítica, do diálogo com a literatura e dos preceitos do campo da ST.

Este estudo obteve aprovação do Comitê de Ética em Pesquisa da Escola Nacional de Saúde Pública Sérgio Arouca.

\section{Resultados e Discussão}

\section{Greve operária e modos de ação sindical: conflitos trabalhistas nas lutas dos trabalhadores no canteiro de obras}

Em 23 de janeiro de 2014, os operários iniciaram a mais longa greve no COMPERJ, encerrada em 27 de março, com duração de 64 dias. O estopim foi, principalmente, as precárias condições sanitárias e de trabalho, como a falta de acesso à água e higienização dos alimentos e desencadeou-se durante o período de negociação do acordo coletivo de 2014-2015.

As condições de trabalho eram as condições principais [...] falta de acesso à água, uma alimentação que está ruim [...]. Claro que como estavam na data base [...] aproveitaram e incluíram também a pauta toda. (Entrevista 2)

Ressalta-se que outros estudos apontam problemas muito semelhantes como motivadores de greves operárias no âmbito de grandes obras da CC, tanto no período de ditadura militar ${ }^{20}$ como em anos recentes ${ }^{3,4}$. 
O Quadro 1 apresenta os principais pontos da pauta sindical de 2014, o estabelecido nos acordos coletivos anteriores e no acordo de 2014-2015 firmado com o término da greve dos operários do COMPERJ. Observa-se o peso e a continuidade dos conflitos trabalhistas especialmente em torno da folgas de campo, horas in itinere, classificação dos ajudantes que exercem atividades profissionais, além de pontos relativos ao aumento salarial, horas extras e bônus da PLR.

As horas in itinere e as folgas de campo foram incluídas nos acordos coletivos de 2011 e 2012, respectivamente, após as greves realizadas nestes anos. Quanto à folga de campo, os operários defendem o direito a cada sessenta dias de trabalho, ampliar os dias de folga e o pagamento das despesas de viagem pelas empresas. Mas, segundo os relatos, era comum o uso de artifícios para o cancelamento da folga de campo como forma de prolongar o tempo de trabalho, em que os dias são remunerados como hora extra ou não ${ }^{10}$.

A compensação monetária de parte do tempo de deslocamento do trabalhador (ida e volta) até o canteiro de obra marca o modo como as horas in itinere foram implantadas no COMPERJ: as empresas remuneram trinta minutos por dia trabalhado em lugar de integrar esse tempo à jornada, o que acarretaria sua redução. Desde então, a pauta sindical manteve esse sentido, tentando ampliar o tempo a ser remunerado como horas in itinere, visto que o tempo efetivamente despendido pelos trabalhados no deslocamento é maior $^{10}$.

Segundo os entrevistados, a convocação para horas extras era uma exigência gerencial das empresas. Sua realização ocorria durante a semana e, comumente, aos sábados, domingos e feriados. Tanto mais para os operários corre-trecho, geralmente empregados por sua vinculação a uma rede de contratação em que essas exigências condicionam sua continuidade nas futuras contratações em obras pelo país.

O pagamento dos valores atrasados da PLR (2013-2014) foi atendido no acordo coletivo firmado com o fim da greve de 2014. Também foi renovada a PLR condicionada a metas individuais e coletivas (Quadro 1), tal como instituída pelas empresas no COMPERJ. Como relatam diferentes trabalhadores, as metas determinam o ritmo de trabalho: "Muita correria para fazer os trabalhos para bater a meta." Trata-se de modos de gerenciamento do trabalho marcados por pressão, intensificação e pelo controle disciplinar: a aplicação de penalidades (advertências) acarreta redução no bônus da PLR, bem como o constrangimento para o trabalhador não se afastar do trabalho, inclusive por motivos de saúde, tanto pelo controle do absenteísmo como pela fixação de "zero acidente de trabalho com afastamento" para a meta "segurança, meio ambiente e saúde"10.

Embora os depoimentos expressem questionamentos à pressão pelo aumento do ritmo, este questionamento permanece difuso. Está ausente uma perspectiva sindical crítica da PLR como prática de gestão estruturada para controle disciplinar e intensificação do trabalho operário. Tal constatação não é exclusiva ao SINTICOM, estando presente no sindicalismo de trabalhadores fabris como na indústria automobilística no Brasil $^{21}$ e nos EUA ${ }^{22}$.

O questionamento operário contra as exigências de tempo de trabalho suplementar resultou em conquistas como as horas in itinere e a folga de campo. A greve de 2014 expressou a continuidade desses conflitos e também a ambiguidade da pauta sindical. Em resposta, as empresas tentam, continuamente, deslocar esse questionamento para a negociação do valor da remuneração do tempo de trabalho suplementar, facilitada pela manutenção de baixos salários nos canteiros de obra com a contenção dos aumentos ou a utilização de profissionais pagos como ajudantes. Esse deslocamento também é favorecido quando a pauta sindical se mantém ambígua ou limitada à compensação monetária do desgaste operário pelo prolongamento e intensificação do tempo de trabalho produzindo sobrecarga laboral e distintos efeitos nocivos à saúde, como apontam alguns estudos na literatura internacional sobre a saúde dos operários da $\mathrm{CC}^{23,24}$.

A reivindicação para classificação profissional ocorre pelo fato das empresas recorrerem ao desvio de função como estratégia de depreciação e desqualificação do trabalho dos operários, remunerando-os com salários de ajudantes. Tratase de prática gerencial para redução dos custos com a força de trabalho como um dos objetivos da terceirização ${ }^{9}$, comum à terceirização da Petrobras $^{25}$.

Com a terceirização, múltiplas empresas operam nos canteiros de obras do COMPERJ, proporcionando diferenças contratuais em termos de salários, condições sanitárias e de trabalho. Nesse cenário, ganha ênfase a "terceirização em

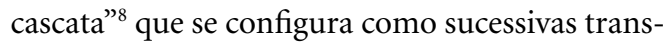
ferências de contrato e subcontratos entre empresas.

Assim como em outras lutas operários do $\mathrm{PAC}^{3,4}$, a ação sindical não caminhou na direção 
Quadro 1. Principais pontos da pauta sindical, acordos coletivos anteriores e do acordo firmado após a greve de 2014 - COMPERJ.

\begin{tabular}{|c|c|c|c|}
\hline Item & Acordos Coletivos anteriores & $\begin{array}{l}\text { Pauta sindical } \\
\text { greve de } 2014\end{array}$ & Acordo Coletivo (2014-2015) \\
\hline Reajuste salarial & - & $11,5 \%$ & $9,0 \%$ \\
\hline Vale Alimentação & $\mathrm{R} \$ 360,00$ & $\mathrm{R} \$ 500,00$ & $\mathrm{R} \$ 444,16$ \\
\hline $\begin{array}{l}\text { Adicional de } \\
\text { horas extras } \\
\text { sobre o valor da } \\
\text { hora normal de } \\
\text { trabalho }\end{array}$ & $\begin{array}{l}50 \% \text { nas duas primeiras horas, de segunda } \\
\text { a sexta-feira } \\
100 \% \text { aos sábados } \\
100 \% \text { aos domingos e feriados }\end{array}$ & $\begin{array}{l}150 \% \text { no valor } \\
\text { das horas extras } \\
\text { nos finais } \\
\text { de semana e } \\
\text { feriados }\end{array}$ & $\begin{array}{l}50 \% \text { nas duas primeiras horas, de segunda a } \\
\text { sexta-feira } \\
100 \% \text { aos sábados } \\
100 \% \text { aos domingos e feriados }\end{array}$ \\
\hline $\begin{array}{l}\text { Horas in Itinere } \\
\text { (Tempo gasto pelo } \\
\text { trabalhador de ida } \\
\text { e volta residência/ } \\
\text { trabalho em local } \\
\text { de difícil acesso) }\end{array}$ & $\begin{array}{l}\text { Pauta conquistada no Acordo Coletivo de } \\
\text { Trabalho (ACT) } 2011 \\
\text { Pagamento de } 30 \text { (trinta) minutos do } \\
\text { salário base de cada trabalhador por dia } \\
\text { trabalhado }\end{array}$ & $\begin{array}{l}\text { Pagamento } \\
\text { de } 02 \text { (duas) } \\
\text { horas por dia } \\
\text { do salário } \\
\text { base de cada } \\
\text { trabalhador por } \\
\text { dia trabalhado }\end{array}$ & $\begin{array}{l}\text { Pagamento de } 30 \text { (trinta) minutos do salário } \\
\text { base de cada trabalhador por dia trabalhado }\end{array}$ \\
\hline $\begin{array}{l}\text { Folgas de campo } \\
\text { (Visita do } \\
\text { trabalhador } \\
\text { migrante aos } \\
\text { familiares depois } \\
\text { de determinado } \\
\text { tempo de } \\
\text { trabalho) }\end{array}$ & $\begin{array}{l}\text { Pauta conquistada no ACT } 2012 \\
\text { Pagamento das despesas da viagem } \\
\text { até a residência após } 90 \text { (noventa) dias } \\
\text { trabalhado. a) distância entre a residência } \\
\text { e o local de trabalho acima ou igual a } \\
1.000 \mathrm{Km} \text { (um mil quilômetros): folga } \\
\text { de } 03 \text { (três) dias úteis de trabalho, com } \\
\text { o fornecimento de transporte aéreo; b) } \\
\text { distância entre a residência e o local de } \\
\text { trabalho inferior a } 1.000 \mathrm{Km} \text { (um mil } \\
\text { quilômetros) e superior ou igual } 500 \\
\text { Km (quinhentos quilômetros): folga } \\
\text { de } 02 \text { (dois) dias úteis de trabalho, com } \\
\text { fornecimento de transporte terrestre } \\
\text { coletivo; e c) distância entre a residência } \\
\text { e o local de trabalho inferior a 500 Km } \\
\text { (quinhentos quilômetros) e superior a } 250 \\
\text { Km (duzentos e quinhentos quilometro): } \\
\text { folga de } 01 \text { (um) dia útil de trabalho, com } \\
\text { fornecimento de transporte terrestre } \\
\end{array}$ & $\begin{array}{l}\text { Redução da } \\
\text { folga de campo } \\
\text { para } 60 \text { dias e o } \\
\text { cumprimento, } \\
\text { por parte } \\
\text { das empresas } \\
\text { terceirizadas, } \\
\text { da cláusula } \\
\text { presente no } \\
\text { ACT }\end{array}$ & Idem ao ACT anterior \\
\hline $\begin{array}{l}\text { Participação } \\
\text { dos Lucros e } \\
\text { Resultados (PLR) }\end{array}$ & $\begin{array}{l}\text { PLR condicionada a metas individuais } \\
\text { ("advertência", "absenteísmo" e "segurança, } \\
\text { meio ambiente e saúde") e coletivas } \\
\text { ("produção" e "produtividade") }\end{array}$ & $\begin{array}{l}\text { Pagamento } \\
\text { integral da PLR } \\
\text { de 2013-2014 }\end{array}$ & $\begin{array}{l}\text { Pagamento das parcelas atrasadas da PLR de } \\
\text { 2013-2014. Mantida a PLR condicionado a } \\
\text { metas individuais ("advertência", "absenteísmo" } \\
\text { e "segurança, meio ambiente e saúde") e } \\
\text { coletivas ("produção" e "produtividade") }\end{array}$ \\
\hline $\begin{array}{l}\text { Classificação } \\
\text { profissional }\end{array}$ & - & $\begin{array}{l}\text { A classificação } \\
\text { dos ajudantes, } \\
\text { a cada seis } \\
\text { meses, que } \\
\text { exercem função } \\
\text { profissional }\end{array}$ & - \\
\hline $\begin{array}{l}\text { Pagamento dos } \\
\text { dias parados na } \\
\text { greve }\end{array}$ & $\begin{array}{l}\text { Descontos dos dias parados ao longo do } \\
\text { ano }\end{array}$ & Não descontar & $\begin{array}{l}\text { O desconto dos dias relativos a greve seriam } \\
\text { descontados ao longo do ano da seguinte } \\
\text { forma: a) } 1 / 3 \text { dos dias }(8,3) \text { serão abonados } \\
\text { pelas empresas; b) } 1 / 3 \text { dos dias }(8,3) \text { serão } \\
\text { compensados; c) } 1 / 3 \text { dos dias }(8,3) \text {, se não } \\
\text { houver paralisação (greve) até } 31 / 01 / 2015 \text {, } \\
\text { serão abonados. Se houver paralisação, os } \\
\text { patrões vão descontar tudo; d) Em casos } \\
\text { de demissão por justa causa ou pedido de } \\
\text { demissão as hipóteses previstas nas letras } \\
\text { "b" e "c" desta cláusula, serão descontadas na } \\
\text { rescisão do contrato de trabalho }\end{array}$ \\
\hline
\end{tabular}


de um questionamento direto à terceirização, embora existissem enfrentamentos aos seus diferentes efeitos, que estão dispersos com a variabilidade de situações de trabalho e condições sanitárias dos trabalhadores ${ }^{10}$.

Segundo os entrevistados, eram comuns "pequenas rebeliões" nos canteiros de obra devido as condições de trabalho e sanitárias como pelos atrasos de pagamentos. Chama-se atenção para as formas de lutas desencadeadas pelos operários, nas palavras de um trabalhador: "tinham toda hora pequenas rebeliões ali dentro", muitas vezes, transformadas em greves.

[...] as coisas surgiam de dentro para fora. Eram rebeliões internas que se transformavam em greves. Eram explosões. Não era uma coisa que o sindicato vai lá, chama assembleia, discutia e organizava. [...] em geral, explodia o negócio. Trabalhadores de um canteiro saiam em passeata, fechavam os outros canteiros ou paravam os ônibus no trevo e todo mundo descia. (Entrevistado 3)

A frequência e a forma assumidas pela resistência operária indicam que as empresas não apresentavam melhorias efetivas às condições reivindicadas. As ações aconteciam por meio de movimentos espontâneos nos canteiros de obra, como "revoltas", "explosões" ou "rebeliões", expressão da ausência de representatividade do sindicato oficial no local de trabalho.

A forma destas lutas subverteram a organização e a gestão empresarial, ao confrontar normas e regras disciplinares, como o de limitar a circulação dos operários entre os canteiros. As revoltas e rebeliões ocorriam durante a jornada, separadamente do sindicato oficial, sem seguir a normatização da legislação, por exemplo, que preconiza aviso prévio de 48 horas para o exercício do "direito de greve". Essas lutas escapam a tentativa do legalismo sindical em prescrever a iniciativa e moderar a ação operária dentro de padrões previsíveis para as empresas. Portanto, diferem das chamadas "greves de adesão passiva", convocadas de fora para dentro da empresa pelo sindicato oficial, geralmente sem participação ativa dos trabalhadores de base na sua organização e execução ${ }^{26}$.

A participação ativa dos operários na organização e condução da greve de 2014 é uma de suas características. Além de sua deflagração à revelia do SINTICOM, os episódios iniciais da greve ampliaram o distanciamento dos trabalhadores de base em relação ao sindicato. Especialmente após a direção sindical, em assembleia com os operários, defender a proposta apresentada pelas empresas para firmar acordo coletivo com o desconto dos dias parados:
[...] a empresa veio meter o desconto dos dias parado e aí, meu irmão, foi quando estourou a revolta lá dentro. [...] porque o sindicato já tinha feito isso com a gente nas primeiras greves de $2012 \mathrm{e}$ 2013. A greve de 2013, nós pagamos até janeiro ou fevereiro de 2014. (Entrevistado 10)

No dia seguinte, 06 (seis) de fevereiro, em outra assembleia, convocada à revelia do sindicato, os operários decidiram pela continuidade da greve, a inclusão da reivindicação de não desconto dos dias parados e elegeram uma Comissão de Base (CB) composta por 11 (onze) trabalhadores na tentativa de participar das negociações com as empresas $^{27}$. Esse movimento contou com o apoio de entidades sindicais como o SINDIPETRO-RJ e a Coordenação Nacional de Lutas (CSP-CONLUTAS).

Os trabalhadores se organizaram na CB de maneira autônoma e separados do SINTICOM. Contudo, sua participação nas negociações foi recusada pelas empresas e pelo SINTICOM. Nesse contexto a greve de 2014 expôs o conflito pela representação dos trabalhadores e diferentes perspectivas paraação sindical em respostas à luta operária.

\section{Resposta à luta operária e diferentes perspectivas para ação sindical: questões para saúde do trabalhador}

As empresas acionaram práticas de vigilância, repressão e demissão para conter ou desarticular o movimento grevista. Uma delas foi a utilização de imagens por meio de câmeras instaladas nos canteiros de obras e nas portarias, ou por celulares de encarregados ou supervisores para identificar líderes e ativistas da greve:

A lataria corria solta [...] geral mandando embora de todas as empresas. Quem estava na cabeça da greve e era filmado [...] eles colocavam câmera para filmar e depois identificavam quem estava ali na frente e mandava embora. (Entrevistado 10)

$\mathrm{Na}$ linguagem dos operários da CC, "lataria" significa demissão em massa. O termo lataria é alusivo às latas de leites em pó descartadas quando não são mais úteis. $O$ relato elenca algumas ações comuns das empresas após a greve, como as demissões dos trabalhadores a perseguição dos líderes ou dos trabalhadores mais ativos na greve. Outra prática relatada é a inserção do nome desses operários demitidos em uma "lista suja":

Disse que tem uma [...] lista suja [...] nas empresas para não aceitar eles [os líderes]. Teve um caso logo no processo da empresa Alusa em que quinze trabalhadores chegaram a fazer exame mé- 
dico [...] quando eles apresentaram a carteira de trabalho, cortaram os quinze. (Entrevistado 6)

De acordo com as entrevistas, a lista é repassada para as demais empresas terceirizadas como forma de marcar esses trabalhadores. Uma ação que se estende no tempo e no espaço, já que as empreiteiras acionam suas redes de empresas contratadas em diferentes regiões do país para impedir a admissão desses operários. Ações de repressão empresarial como vigiar, demitir e marcar líderes grevistas estão presentes na história de luta dos trabalhadores ${ }^{28}$, nas obras da CC durante a ditadura militar ${ }^{20}$, nas greves anteriores do COMPERJ ${ }^{5}$, em outras obras do PAC $^{3,4}$ e entre os terceirizados em refinarias da Petrobrás ${ }^{25}$.

A resposta estatal à greve compreendeu o emprego dos aparelhos repressivos por meio da polícia militar e da Justiça do Trabalho. A polícia manteve uma ação ostensiva nas atividades grevistas, nas assembleias e em atos realizados nos canteiros de obras e na rodovia ("Trevo da reta") na entrada do COMPERJ ou mesmo em participação dos trabalhadores nas audiências públicas promovidas pelo MPT e pela Assembleia Legislativa do Estado do Rio de Janeiro. Por meio de liminar, em 27 de fevereiro de 2014, o Tribunal Regional do Trabalho considerou a greve abusiva, determinando o retorno imediato ao trabalho sob pena de multa diária de dez mil reais para o SINTICOM ${ }^{29}$.

Apesar dessas medidas, igualmente adotadas em outros movimentos grevistas, nas obras do COMPERJ ${ }^{5}$ e do $\mathrm{PAC}^{3,4}$, a greve prosseguiu. Tal decisão foi tomada em assembleias operárias, apartadas do sindicato oficial. A CB atuava mediante atos e mobilizações na porta da obra, tentando manter a greve dos trabalhadores.

Uma das opções da CB, e das entidades sindicais apoiadoras, foi encaminhar as demandas dos trabalhadores para o MPT com perspectiva de obter o reconhecimento da Comissão para representação dos trabalhadores nas negociações com as empresas.

Uma ação estatal para conciliar o conflito trabalhista do COMPERJ foi empreendida pelo $\mathrm{MPT}^{27}$ recorrendo às audiências públicas. Iniciativa sem sucesso já que as empresas se recusaram a participar de tais audiências. $\mathrm{O}$ envolvimento da CB nas negociações, já repelido pelas empresas, foi publicamente recusado pelo SINTICOM. Os diretores não reconheceram a legitimidade da CB dos operários do COMPERJ. Em seu lugar, sustentaram a prerrogativa legal conferida ao SINTICOM e de outra comissão de trabalhadores.
Tratava-se da Comissão de Representatividade Sindical (CRS) incluída no chamado Compromisso Nacional para Aperfeiçoar as Condições de Trabalho na Indústria da Construção Civil $(\mathrm{CNIC})^{30}$, instituída em 2012. O Compromisso resultou da iniciativa do governo federal, por meio da Secretaria Geral da Presidência da República, em promover a Mesa de Diálogo e Negociação Tripartite entre representantes do governo federal, das grandes empreiteiras e das centrais sindicais reconhecidas pela Lei $11.648 / 08^{31}$, em resposta às greves operárias ocorridas, em 2011, nas obras do $\mathrm{PAC}^{30}$.

O Compromisso ganhou status de "política pública" para o setor da CC pesada com objetivo de garantir a produtividade das empresas e conter os conflitos (greves) que paralisavam as grandes obras. Segundo o então presidente da CUT, o Compromisso “[...] estabelece regras e padrões nacionais para os salários e condições de trabalho, saúde e segurança dos operários da construção. [...] à medida que o Compromisso for sendo aplicado no dia-a-dia, o número de greves tende a diminuir $[\ldots]^{32}$.

A continuidade dos conflitos e das greves operárias da $\mathrm{CC}^{3,4}$, como a do COMPERJ analisada neste estudo, questionou o CNIC como política pública capaz de promover melhoria nas condições de trabalho e saúde dos trabalhadores. Cabe salientar, uma política que desconsiderou o conhecimento produzido pela $\mathrm{ST}^{33}$. Ressalta-se a ação sindical institucional com claro compromisso da moderação política e garantia do pacto pelo crescimento econômico com Estado e patronato, uma ação tipificada como própria a um sindicalismo de parceria com o capital ${ }^{34}$ também presente em parte do sindicalismo nos $\mathrm{EUA}^{22}$ nas últimas décadas.

Esse é o contexto em que emerge a CRS em colaboração com as empresas nos canteiros de obras, orientada para construir um ambiente de trabalho saudável, propício ao aumento da produtividade ${ }^{30}$. Os relatos dos operários do COMPERJ ilustram o papel de controle e desorganização das lutas dos trabalhadores pela CRS chancelado pelas empresas e pelo SINTICOM:

A comissão [CRS] virou tipo um fiscal dentro do canteiro [...] e aponta [...] as pessoas que são questionadoras. [...] essa greve tinha muito revolta com a comissão (Entrevistado 6).

Essa perspectiva sindical da CRS tem inspiração nas atuais comissões de fábrica dos metalúrgicos do ABC-SP, orientada pela busca em viabilizar os ganhos de produtividade das empresas com benefícios nos contratos de trabalho ou em 
compatibilizar produtividade e saúde. A defesa dessa política sindical oculta a aceitação da intensificação da exploração da força de trabalho pelo capital, expressão do enraizamento da ideologia liberal (burguesa) no movimento sindical ${ }^{35}$.

A ideologia burguesa subjaz a perspectiva sindical da CRS como organização investida e reconhecida pelo Estado para representar e participar de negociações em nome dos trabalhadores. É o Estado quem outorga e garante o monopólio da representação do SINTICOM e da CRS, e não os próprios operários ${ }^{36}$.

O Estado também determina a representação sindical por categoria profissional, outro fundamento do atrelamento sindical ao Estado $^{36}$ que fragmenta os trabalhadores. Fragmentação ampliada com a terceirização, ainda mais com a Lei 13.429/2017 e a reforma trabalhista (13.467/2017). Entre os apoiadores da CB, constatamos a presença de uma perspectiva crítica à divisão da organização sindical por categoria profissional.

Trabalhou dentro da indústria de petróleo, para nós tinha que ser petroleiro. [...] essa divisão é uma coisa que existe para manipular os trabalhadores, para desorganizar a gente [...] que o Estado impõe, porque não é uma opção dos trabalhadores, é uma imposição legal. Então, nós vamos apoiar a luta, participar, ajudar a organizar (Entrevistado 3)

Pode-se dizer que a greve dos operários do COMPERJ esboçou um questionamento às características da estrutura sindical brasileira. Um esboço, todavia, inconcluso. A CB emergiu na luta direta e por decisão dos próprios operários, com participação ativa dos trabalhadores em sua organização, contrastando com a passividade da ação do sindicato oficial. Entretanto, a força do movimento não foi suficiente para impor a negociação direta pela $\mathrm{CB}$ às empresas, nem mesmo com o empenho da própria $\mathrm{CB}$ em buscar junto ao MPT seu reconhecimento como representante dos trabalhadores. A recusa das empresas em negociar com a CB representa a política de negação da organização própria dos operários nos locais de trabalho, bem como de apoio a estrutura sindical de Estado expresso pelo reconhecimento do sindicato oficial.

\section{Considerações finais}

Nesse estudo, realizou-se uma breve reconstrução das lutas sociais realizadas pelos operários do COMPERJ sob a perspectiva dos próprios trabalhadores. Ganhou destaque o importante papel da CB no resgate do protagonismo operário. Tal assunção coletiva pode ser interpretada como desobediência e questionamento operário às antigas estruturas burocráticas do modelo sindical e ao aparato das empresas. A reação dos trabalhadores de base pode ser vista como um dos efeitos da política de conciliação de classes e parceria com o capital, empreendida pelo governo do PT e assumida pelas direções dos sindicatos da CUT e das principais Centrais Sindicais do país ${ }^{34}$.

Embora algumas reivindicações estivessem previstas na legislação trabalhista, foi a luta operária que garantiu importantes conquistas como a folga de campo. A Reforma Trabalhista, aprovada em 2017, extinguiu e reduziu direitos dos trabalhadores ${ }^{38}$, o que traz maiores adversidade a eles, mas não impossibilita sua conquista.

No COMPERJ, as empresas, em resposta a greve dos trabalhadores, produziram uma série de ações com objetivo de enfraquecer, desarticular e dissolver o movimento com demissões de líderes da CB e a produção de "listas sujas" como forma de identificar lideranças operárias em futuras contratações. Como salienta Rodrigues ${ }^{39}$, na experiência histórica de organização dos trabalhadores, nos locais de trabalho no Brasil, muitas comissões emergiam e foram constituídas para organização e negociação da greve, mas, passado este momento desapareceram, seja por demissão dos operários ou por falta de apoio do sindicato oficial.

Apesar das mobilizações, a força do movimento paredista não foi suficiente para impor a negociação direta pela $\mathrm{CB}$ às empresas. $\mathrm{A} C \mathrm{CB}$ e seus apoiadores encaminharam esforços na direção do MPT para obter seu reconhecimento como representantes dos trabalhadores nas negociações, uma ação ainda nos marcos do aparato de Estado, e não pela conquista dos próprios operários.

O presente artigo enfatiza a importância dos estudos do campo de ST sobre as implicações da estrutura sindical do Estado na organização e mobilização dos trabalhadores, estes enquanto classe, na luta pela saúde. Cumpre ainda a observação das medidas advindas da reforma trabalhista, que mudaram o sistema de organização sindical, acarretando maiores desafios para esta classe $^{38}$. Nesse cenário, os sindicatos e partidos de base operária precisam ser reconstruídos estruturando-se em uma perspectiva de classe trabalhadora ${ }^{22}$ com unificação entre empregados e desempregados.

Por fim, deve-se aprender, sempre, com a inteligência dos movimentos operários, pois toda 
ação de massa é educativa e motiva mais gente para a luta ${ }^{13}$. Registre-se mais uma página na história operária em que os trabalhadores, sincronicamente, lutam e defendem a saúde, buscando a melhoria das condições de trabalho, possibilidades de transformação social, se contrapondo à dominação e ao controle do capital em um cenário de disputa pela hegemonia sindical.

\section{Colaboradores}

HP Almeida foi responsável pelo desenho do projeto, revisão bibliográfica, coleta, análise e interpretação dos dados. KR Souza e JA Pina foram responsáveis pelo desenho do projeto, revisão bibliográfica, análise e interpretação, desenvolvimento do manuscrito e aprovação final da versão publicada.

\section{Referências}

1. Paulani LM. A experiência brasileira entre 2003 e 2014: Neodesenvolvimentismo? Cadernos do Desenvolvimento 2017 ; 12(20):135-155.

2. Granemann S. PAC: a afirmação do parasitismo do capital sobre o trabalho. Rev Políticas Públicas 2007; 11(1):1-19.

3. Campos C. Conflitos trabalhistas nas obras do PAC:o caso das Usinas Hidrelétricas de Jirau, Santo Antônio e Belo Monte [dissertação]. Campinas: Universidade Estadual de Campinas; 2016.

4. Véras R. Brasil em obras, peões em luta, sindicatos surpreendidos. Rev Crit Cienc Sociais 2014; 103:111136.

5. Lima RCV. Desenvolvimento e Contradições Sociais no Brasil contemporâneo. Um estudo do Complexo Petroquímico do Rio de Janeiro - COMPERJ [dissertação]. Araraquara: Universidade Estadual Paulista; 2015.

6. Departamento Intersindical de Estatística e Estudos Socioeconômicos (DIEESE). Estudos e Pesquisa: Estudo Setorial da Construção 2012. São Paulo: DIEESE; 2013.

7. Alencar E, Galdo R. Trinta mil operários de vários estados do país 'correm trecho' em busca do tesouro. Jornal O Globo 2014 Abr 6; p. 17.

8. Marx K. O capital: crítica da economia política. São Paulo: Boitempo; 2013.

9. Marcelino P, Cavalcante S. Por uma definição de terceirização. Cad CRH 2012; 25(65):331-346.

10. Almeida HP, Souza KR, Pina JA. Trabalho e saúde nas lutas dos operários da construção civil do Complexo Petroquímico do Rio de Janeiro. Rev Bras Saúde Ocup 2018; 43(0):1-8.

11. Hobsbawm EJ. Mundos do trabalho: novos estudos sobre história operária. $3^{a}$ ed. São Paulo: Paz e Terra; 2000.

12. Laurell AC. Saúde e Trabalho: os enfoques teóricos. In: Nunes ED, García JC, organizadores. As Ciências Sociais em Saúde na América Latina. Brasília: OPAS; 1985. p. 255-76.

13. Luxemburgo R. Greve de massa, partido e sindicato. Coimbra: Centelha; 1974. 
14. Gramsci A. Cadernos do cárcere. Rio de Janeiro: Civilização Brasileira; 2004.

15. Lênin VI. Sobre as greves. In: Lênin VI, organizador. Sobre os sindicatos. Rio de Janeiro: Vitória; 1961. p. 39-47.

16. Oddone I, Marri G, Gloria S, Briante G, Chiattella M, Re A. Ambiente de trabalho: a luta dos trabalhadores pela saúde. São Paulo: Editora Hucitec; 1986.

17. Brandão CR. Reflexões sobre como fazer trabalho de campo. Soc Cult 2007; 10(1):11-27.

18. Bisol CA. Estratégias de pesquisa em contextos de diversidade cultural: entrevistas de listagem livre, entrevistas com informantes-chave e grupos focais. Estud Psicol 2012; 29:719-726.

19. Brandão CR. A pergunta a várias mãos: a experiência da pesquisa no trabalho do educador. São Paulo: Cortez; 2003.

20. Valladares LP. Quebra-Quebras na construção civil: o caso dos operários do metro do Rio de Janeiro. Dados 1981; 24(1):61-84.

21. Pina JA, Stotz EN, Jackson Filho JM. Trabalhador "compatível", fratura exposta no processo de produção da indústria automobilística: intensificação do trabalho e saúde em questão. Cad Saude Publica 2018; 34(7):1-13.

22. Yeats M. COVID-19, Economic Depression, and the Black Lives Matter Protests. Will the Triple Crisis Bring a Working-Class Revolt in the United States? Monthly Review [periódico na Internet]. 2020 Set [cited 2020 Nov 25]; 72(4). Available from: https:// monthlyreview.org/2020/09/01/covid-19-economicdepression-and-the-black-lives-matter-protests/

23. Holden S, Sunindijo RY. Technology, Long Work Hours, and Stress Worsen Work-life Balance in the Construction Industry. Intern Journal Integrated Engineering. 2018; 10(2):13-18.

24. Kotera Y, Green P, Sheffield D. Work-life balance of UK construction workers: relationship with mental health. Construction Management and Economics 2020; 38(3):291-303.

25. Araújo AJS. Paradoxos da modernização: terceirização e segurança dos trabalhadores em uma refinaria de petróleo [tese]. Rio de Janeiro: Escola Nacional de Saúde Pública Sergio Arouca/Fundação Oswaldo Cruz; 2001.

26. Boito Jr. A. Reforma e Persistência da Estrutura Sindical. In: Boito Jr. A, organizador. O Sindicalismo Brasileiro nos anos 80. Rio de Janeiro: Paz e Terra; 1991. p. 43-91.

27. Ministério Público do Trabalho. Procuradoria Regional do Trabalho (PRT) $-1^{\circ}$ Região de Niterói; 2014, $11 \mathrm{fev}$.

28. Edelman B. A Legalização da Classe Operária. São Paulo: Boitempo; 2016.
29. Ordoñez R. Justiça considera ilegal greve dos trabalhadores do Comperj. Jornal O Globo 2014 Fev 27.

30. Departamento Intersindical de Estatística e Estudos Socioeconômicos (DIEESE). Mesa Nacional da Construção O diálogo social tripartite - rumo a condições de trabalho decentes no setor da construção. São Paulo: DIEESE; 2013.

31. Brasil. Lei $\mathrm{n}^{\circ} 11.648$ de 31 de março de 2008. Dispõe sobre o reconhecimento formal das centrais sindicais para os fins que especifica. Diário Oficial da União 2008, 31 mar.

32. Santos A. Um compromisso para construir o Brasil. Revista Carta Maior [revista na internet]; 2012 [acessado 2016 jan 21]. Disponível em: http://cartamaior. com.br/?/Opiniao/Um-compromisso-para-construir -o-Brasil/26578

33. Lacaz FAC. Saúde do trabalhador: um estudo sobre as formações discursivas da academia dos serviços e do movimento sindical [tese]. Campinas: Universidade Estadual de Campinas; 1996.

34. Galvão A. A contribuição do debate sobre a revitalização sindical para a análise do sindicalismo brasileiro. Rev Crítica Marxista 2014;(38):p. 103-117.

35. Stotz EN, Pina JA. Experiência operária e ciência na luta pela saúde e a emancipação social. Rev Bras Saude Ocup 2017; 42(e12):1-11.

36. Boito Jr. A. O sindicalismo de estado no Brasil: uma análise crítica da estrutura sindical. Campinas: Hucitec/Unicamp; 1991.

37. Krein JD. O desmonte dos direitos, as novas configurações do trabalho e o esvaziamento da ação coletiva: consequências da reforma trabalhista. Tempo Soc 2018; 30(1):77-104.

38. Rodrigues IJ. As comissões de empresa e o movimento sindical. In: Boito Jr. A,organizador. O Sindicalismo Brasileiro nos anos 80. Rio de Janeiro: Paz e Terra; 1991. p. 137-170.

Artigo apresentado em 30/06/2020

Aprovado em 15/07/2021

Versão final apresentada em 17/07/2021

Editores-chefes: Romeu Gomes, Antônio Augusto Moura da Silva 